\title{
Literature Review on Differential Evolution Algorithm
}

\section{SadeerFadhilOudah}

PhD Candidate in Operations Research, faculty of graduate studies for statistical research, Cairo University, Egypt.

\section{Prof. Dr. HegazyZaher}

Professor Doctor in Mathematical statistics, faculty of graduate studies for statistical research, Cairo University, Egypt.

\section{Assoc. Prof. Dr. NaglaaRagaaSaeid Hassan}

Associate Professor in Operations Research, faculty of graduate studies for statistical research, Cairo University, Egypt.

\section{Dr. EmanOun}

Doctor in Operations Research, faculty of graduate studies for statistical research, Cairo University, Egypt.

\section{Abstract}

Differential evolution algorithm is one of the most efficient metaheuristic approaches. In this paper, a review and analysis is presented in order to help for future research in differential evolution algorithm. It covers an analysis of about 142 papers of the previous work in the modifications of the algorithm including the main parameters of the classical steps of the algorithm and hybridization with other algorithms. The analysis also shows the applications that optimized using the differential evolution algorithm.

\section{Introduction}

Metaheuristic is an old Greek word that contains two words. The first one is the word Meta, which means high level. The second word is Heuristic, which means to search. In operations research and artificial intelligence, the word metaheuristic is related to finding solutions of the optimization problems using random search and local search. The history of metaheuristics return back to 1950 (Sörensen et al., 2018). This paper discusses a review on one of the metaheuristic approaches called differential evolution algorithm. Such algorithm is developed by Storn and Price(Storn \& Price, 1996). The differential evolution algorithm begins by generating population of candidate solutions. The solutions are obtained by combining the existing solutions in the population using a simple formula. Then the algorithm determine whichever solution is the best. The differential evolution algorithm seems very like the genetic algorithm in its steps, where it utilizes the current solutions in the population by mutating them and using crossover techniques.Figure 1 shows the flowchart of the differential evolution algorithm. The paper is organized in four sections as follows. Section 2 shows the literature review of the differential evolution algorithm. Section 3 shows the analysis of the literature review. Section 4 presents the conclusion. 


\section{Literature review}

DE performance is confined by specified mutation and crossover strategies and the associated control parameters (mutation scale factor F, crossover constant CR and population size NP). Therefore, researchers have been adapting modern techniques to improve the performance and to overcome problems of classic DE. In this section, a literature review is presented to show the previous work that developed on the DE algorithm. The section contains three sub-sections. The first one presents the previous work that developed to modify the classic DE. The second sub-section shows the previous work that presented on the hybridization with the other algorithms. The third section shows the applications that solved using DE.

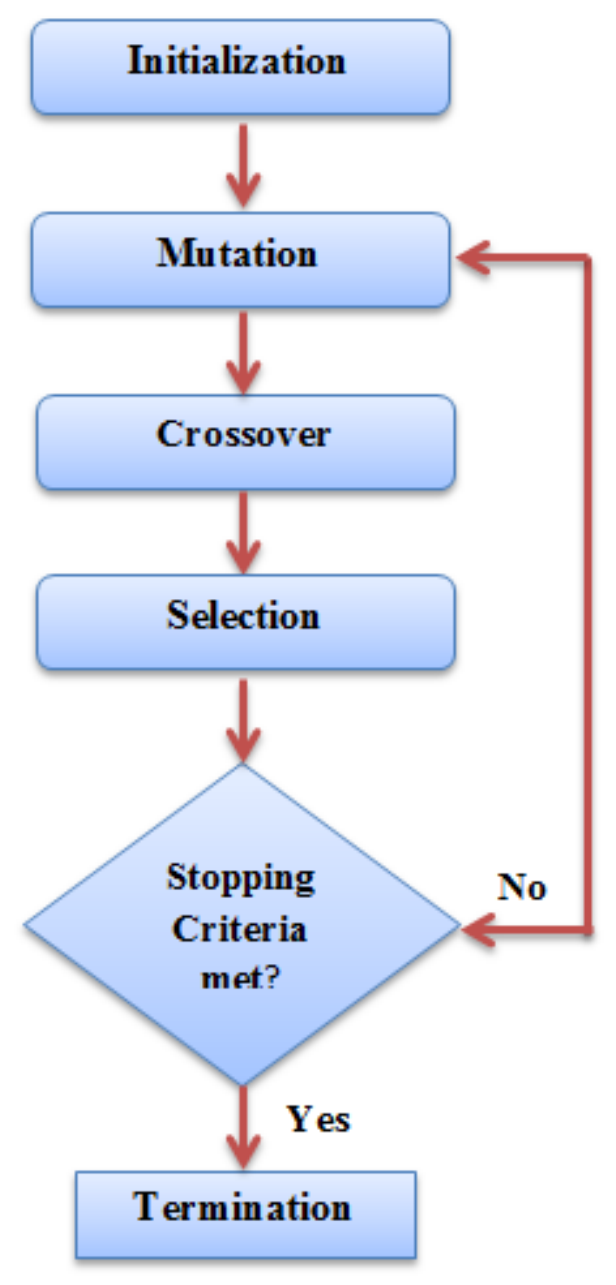

Figure 1: The flowchart of the differential evolution algorithm

\subsection{Modifications of the classic DE}

This sub-section shows the previous work presented in the modifications of DE. Qin, Huang, and Suganthan(2008) proposed a self-adaptive DE (SaDE) algorithm, in which both trial vector generation strategies and their associated control parameter values are gradually self- 
adapted by learning from their previous experiences in generating promising solutions. Das et al.(2009)suggestedtwo types of topological local DE models to attainproper ratiobetween the explorative and exploitative techniques of DE, called DEGL. Two trail vectors were generated by mutating the global and local neighborhood and combined to formulate an actual trial vector by employing a weight factor.Gong et al. (Gong et al., 2010)presented a family of improved DE that attempts to adaptively choose a more suitable strategy.Brest and Maucec(Brest \& Maučec, 2011)proposed a 'self-adaptive differential evolution algorithm’ called jDElscop.

Mallipeddi et al.(2011)developed the so-called EPSDE, self-adaptive DE, which relies on ensemble approach. A group of distinct mutation approaches with a group of values for each control parameters are generated and competed to each other through the evaluation process to produce better outcomes.Wang, Cai, and Zhang(2011)introduced a composite DE (CoDE) approach which randomly combines three strategies of trial vectors generation alongside using three control parameters settings. L. Wang et al. (2012) proposed a novel modified binary differential evolution algorithm (NMBDE). Caraffini et al.(2013)proposed a memetic strategy called (SMADE), Super-fit Multi-criteria Adaptive DE based on the Multi-criteria Adaptive DE (MADE). Tanabe and Fukunaga(2013)proposed parameter adaptation that is based on the historical memory of the successful control parameter settings to guide the values of the future control parameters. Tanabe and Fukunaga(Tanabe \& Fukunaga, 2014) developed an adaptation of DE using linear population size reduction that decreases the population size gradually using linear function.Cortés-Antonio et al.(2014) presents the results of implementation of differential evolution algorithm on a field programmable gate array device (FPGA) using floating point representation with double precision.Ali Wagdy Mohamed(Ali Wagdy Mohamed, 2015) introduced a triangular mutation rule based on convex combination vector.Wu et al. (Wu et al., 2016)introduced a multi-population-based structure to identify an adapted collection of threemutation strategies. The population is dynamically dividedinto severalsub-populations includingone reward sub-population and three indicator sub-populations. Each sub-population's indicator, with a comparativelysmaller size, is assigned to acomponentmutation strategy, while the reward sub-population, with a relatively larger size,is allocated to the current-best performed mutationapproach as an extra reward. Consequently, an allocation of dynamic computational source among themutation strategiesis created.

Ali W Mohamed et al.(2017)modified of Tanabe and Fukunaga(Tanabe \& Fukunaga, 2014) algorithm by utilizing different adaption approach for the selection of control parameters.Ali Wagdy Mohamed(2017) introduced a study to measure the difference between the worst and the best solutions at a generation. They combined directed mutation rule with the improved basic mutation technique. The study objective was to increase the ability of local search of the basic DE and to obtain a better balance between robustness and convergence rate. Akararungruangkul \& Kaewman(2018) modified two points in the original DE, which are the mutation formula is introduced and the rule of local search.Ali W. Mohamed et al. (Ali W. Mohamed et al., 2019)demonstrated a new triangular mutation rule relies on the convex 
integration vector of the three randomly selected vectors as well as the difference vector between the worst and best individuals among the triple stochastic vectors.Meng et al. (2019)proposed an algorithm, which is pointed to address some of the weaknesses of classic DE and the improved ones. Such as, lack in a given mutation approach and inappropriate control parameters adaptation schemes.

Stanovov et al.(2020) proposeda new parameter control scheme for the differential evolution algorithm. The developed linear bias reduction scheme controls the Lehmer mean parameter value depending on the optimization stage allowing the algorithm to improve the exploration properties at the beginning of the search and speed up the exploitation at the end of the search. As a basic algorithm, the L-SHADE approach is considered, as well as its modifications, namely the jSO and DISH algorithms.Centeno-Telleria et al. (2021) to present a consistent methodology for tuning optimal parameters. At the heart of the methodology is the use of an artificial neural network (ANN) that learns to draw links between the algorithm performance and parameter values. Table 1: Different Modification of DE .

Table 1: Different Modification of DE.

\begin{tabular}{|l|c|l|}
\hline \multicolumn{1}{|c|}{ Contribution } & $\begin{array}{c}\text { NO. of } \\
\text { Contribution }\end{array}$ & \multicolumn{1}{|c|}{ Year } \\
\hline Population & 2 & 2014, 2016 \\
\hline $\begin{array}{l}\text { Learning } \\
\text { procedures }\end{array}$ & 9 & $\begin{array}{l}\text { 2010, 2011, 2012, 2013, 2014, 2016, } \\
\text { 2017, 2020 }\end{array}$ \\
\hline $\begin{array}{l}\text { Mutation } \\
\text { functions }\end{array}$ & 8 & 2009, 2011, 2015, 2016, 2017, 2018, 2019 \\
\hline $\begin{array}{l}\text { control } \\
\text { parameters }\end{array}$ & 8 & 2008, 2011, 2013, 2017, 2019, 2020, 2021 \\
\hline $\begin{array}{l}\text { Vector } \\
\text { generation }\end{array}$ & 4 & 2008, 2009, 2011 \\
\hline
\end{tabular}

\subsection{Hybridization with other algorithms}

This sub-section shows the literatures review about the recent published researches hybridization of DE Algorithm with other algorithms. where Hybridization is another important modification in DE which is implemented to enhance its performance and convergence speed. Plenty of work can be found in the literature on the hybridization of DE. Pant et al. (2008) also proposed a hybrid version of DE with particle swarm optimization and results show that the proposed DE-PSO is quite competent for solving the considered test functions as well as real-life problems.Ali et al. (2009)hybridized the Ant Colony Algorithm with DE and applied it on problems related to water resources. Gong et al. (2010) proposed a hybridization between DE and biography-based optimization (BBO). The method produced a noticeable result through integration of BBO exploitation with DE exploration. X. Wang and Xu (2011)proposed hybrid DE Algorithm that uses hill climbing heuristic for solving traveling salesman problem.Gao 
andLiu (2011)developed a hybridization betweenthe artificial bee colony and DE algorithms.El Dor et al. (2012) hybridized particle swarm optimization with DE for enhancing the algorithm.

Cui et al.(2013) proposed a hybrid differential evolution harmony search algorithm for numerical optimization problems.Rahmat and Musirin (2013)presented a differential evolution immunized ant colony optimization technique in solving economic load dispatch problem. Fister Jr et al. (2013) proposed a hybrid bat algorithm with the DE algorithm. Saruhan (2014) proposed differential evolution and simulated annealing algorithms for mechanical systems design. Addawe and Magadia (2014)proposed differential evolution and simulated annealing algorithms for fitting autoregressive models to data. Fouad (2014)proposed a novel hybrid genetic differential evolution algorithm for constrained optimization problems.Sabar et al. (2015)developedhybrid DEalgorithm that uses game theoryto control the selection of mutation parameters during the search process. X. Meng et al.(2015) proposed a hybrid bat algorithm with DEalgorithm for constrained optimization problems. Sarbazfard and Jafarian(2016) presented ahybrid algorithm based on firefly algorithm and DE for global optimization problems. Z. Zhang et al. ((2016) hybridized cuckoo search and krill herd optimization with DE.

Mlakar et al. (2016)proposed a hybrid differential evolution by using a switchingprobability strategy of Cuckoo search and applied it for multi-level image thresholding.MohammadZadeh and Sadjadi(2017) presented a hybrid firefly and DE algorithm for optimization of a mixed repairable and non-repairable system reliability problem.Jadon et al. (2017)used a hybrid artificial bee colony algorithm with DE. Nama and Saha(2018)proposed a hybrid DE algorithm with backtracking search optimization algorithm for solving optimization problems.Chen et al.(2018) proposed a hybrid expert system based on sleep event's threshold dependencies for automated personalized sleep staging by combining symbolic fusion and DE algorithm.Zhang et al. (2018) presented Differential-Evolution-Based Coevolution Ant Colony Optimization Algorithm for Bayesian Network Structure Learning. Naz et al. (Naz et al., 2018) introduced a hybrid gray wolf differential evolution algorithm to minimize the peak load demand electricity cost. Z. Zhang et al. (2019) used a hybrid optimization algorithm based on cuckoo search and differential evolution for solving constrained engineering problems.Liu et al. (2019)presented a hybrid differential evolution based on the random walk of ants around the ant lion is presented, which combines the advantages of ant lion optimization algorithm and differential evolution, aiming to well balance the exploitation and exploration of the search.Reddy(2019)proposed an approach for solving the optimal power flow problem using hybrid DE with harmony search algorithm. Chi et al. (2019)presented a hybridization of cuckoo search and differential evolution for the logistics distribution center location problem.Sethanan and Jamrus (2020) presented a hybrid differential evolution algorithm involving a genetic operator with fuzzy logic controller for solving the multi-trip vehicle routing problem with backhauls and a heterogeneous fleet.Pan et al. (2020) presented a hybrid differential evolution algorithm combining two previous modified DE algorithms. M. Liu et al.(2020) a hybrid whale optimization algorithm enhanced with Levy flight and differential evolution. Ahmadianfar et al. 
(2021)developed a hybrid DE with particle swarm optimization algorithm for solving operating rules for multi-reservoir hydropower generation systems.Mohsin et al. (2021)proposed a hybrid optimization algorithm based on DE and grey wolf optimizer. Ding et al. (2021) proposed a hybridized algorithm between the differential evolution and black hole algorithms.

\subsection{Applications of DE}

The DE since 1996 has become a very powerful method to solve a wide range of scientific problems, including computer science, physics, signal processing, shape optimization, control science, manufacturing, management, traffic control and economics (Shamekhi, 2013). In this sub-section, a literature review is presented to show the applications that were solved using DE. Table 2 shows the applications of DE in the electrical and power systems. Table 3 shows the applications of DE in the manufacturing science and operations research. Table 4 shows the applications of DE in the Robotics and Expert Systems. Table 5 shows the applications of DE in robotics and expert systems. Table 6 shows the applications of DE in pattern recognition. Table 7 shows the applications of DE in image processing. Table 8 shows the applications of DE in the bioinformatics and bio-medical engineering. Table 9 shows the applications of DE in electronics and communication engineering.Figure2shows diverging Radial graph of DE applications in different areas.

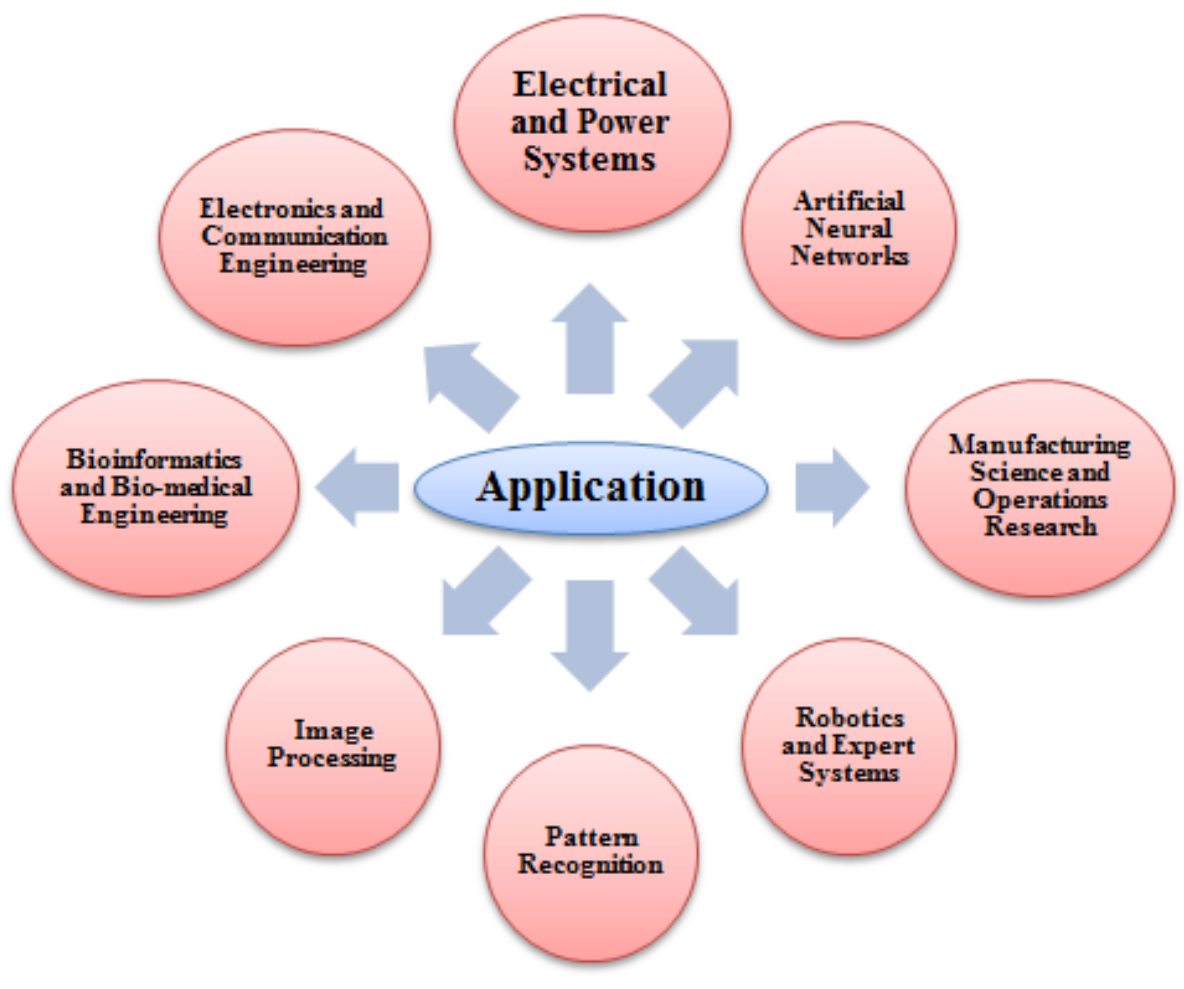

Figure 2: Diverging Radial graph of DE applications in different areas. 
Table 2: Electrical and Power Systems

\begin{tabular}{|l|l|}
\hline \multicolumn{1}{|c|}{ Authors } & \multicolumn{1}{|c}{ Applications } \\
\cline { 1 - 1 } Bhattacharya and Chattopadhyay(2010) & \multirow{2}{*}{ Economic Dispatch } \\
\cline { 1 - 1 } Basu(2011) & \\
\cline { 1 - 1 } Sayah and Hamouda(2011) & \\
\cline { 1 - 1 } Aktulga et al.(2012) & \\
\cline { 1 - 1 } Azad et al.(2012) & Power System Stabilizer \\
\hline Glotić and Zamuda(2015) & Fault Diagnosis \\
\hline Pandit et al.(2015) & Power Distribution Reconfiguration \\
\hline Ghasemi et al.(2016) & \multirow{2}{*}{ Optimal Power Flow } \\
\hline T. Wang et al.(2014) & \\
\hline Prado et al.(2014) & \\
\hline Sivasubramani and Swarup(2012) & \\
\hline Birogul(2019) & \\
\hline
\end{tabular}

Table 3: Artificial Neural Networks

\begin{tabular}{|c|c|}
\hline Authors & Applications \\
\hline Dragoi et al.(2013) & \multirow{2}{*}{ Optimal Network Topology } \\
\hline Singh et al.(2020) & \\
\hline Dhahri et al. (2012) & \multirow{3}{*}{$\begin{array}{l}\text { Designing of Different Variants of Neural } \\
\text { Networks }\end{array}$} \\
\hline B. Wang et al.(2018) & \\
\hline Balamurugan et al. (2021) & \\
\hline Subudhi \& Jena(2011) & \multirow{2}{*}{ Neural Network Training } \\
\hline Piotrowski(2014) & \\
\hline Lu et al.(2012) & Fuzzy Neural Net Controller \\
\hline U. P. Singh and Jain(2018) & $\begin{array}{l}\text { Neural Network for Non linear System } \\
\text { Identification }\end{array}$ \\
\hline
\end{tabular}

Table 4: Manufacturing Science and Operations Research

\begin{tabular}{|l|l|}
\hline \multicolumn{1}{|c|}{ Authors } & \multicolumn{1}{c|}{ Applications } \\
\cline { 1 - 1 } G. Zhang et al.(2013) & Manufacturing Process Optimization \\
\cline { 1 - 1 } Yildiz(2013a) & $\begin{array}{l}\text { Transport Sequencing in Cross Docking } \\
\text { Systems }\end{array}$ \\
\hline Liao et al.(2012) & \multirow{2}{*}{ Scheduling } \\
\cline { 1 - 1 } Yildiz(2013b) & \\
\cline { 1 - 1 } Vincent and Ponnambalam(2012) & \\
\cline { 1 - 1 } Ponsich and Coello(2013) & \\
\cline { 1 - 1 } W.-L. Wang et al.(2013) & \\
\cline { 1 - 1 } Tang et al.(2013) &
\end{tabular}




\begin{tabular}{|l|l|}
\hline \multicolumn{1}{|c|}{ Authors } & \multicolumn{1}{c|}{ Applications } \\
\cline { 1 - 2 } Glotić et al.(2014) & \multirow{2}{*}{ Scheduling } \\
\cline { 1 - 2 } M. Liu et al.(2020) & Ship route planning and marine safety \\
\hline Zhao et al.(2014) & speed control of brushless direct-current motor \\
\hline Jigang et al.(2019)
\end{tabular}

Table 5: Robotics and Expert Systems

\begin{tabular}{|l|l|}
\hline \multicolumn{1}{|c|}{ Authors } & \multicolumn{1}{c|}{ Applications } \\
\cline { 1 - 1 } Vasile et al.(2011) & \multirow{2}{*}{ Space Trajectory Optimization } \\
\cline { 1 - 1 } Das et al.(2016) & \multicolumn{1}{|c|}{ Route Planning/Guidance of Unmanned Vehicles } \\
\cline { 1 - 2 } Raghunathan and Ghose(2014) & Satellite Orbit Reconfiguration \\
\cline { 1 - 2 } Zamuda and Sosa(2014) & Part based Work Piece Detection \\
\cline { 1 - 2 } Y. Chen et al.(2015) & Real Time Object Tracking \\
\hline Cay et al.(2015) & Object Detection \\
\hline Ugolotti et al.(2013) & Body Pose Estimation \\
\hline Ugolotti and Cagnoni(2013) & Financial Market Dynamics \\
\hline Hachicha et al.(2011) & Neural Fuzzy Inference System \\
\hline C.-H. Chen and Yang(2014) & expert system for underwater glider path planning \\
\cline { 1 - 1 } Zamuda\& Sosa(2019) & \\
\hline
\end{tabular}

Table 6: Pattern Recognition

\begin{tabular}{|c|c|}
\hline Authors & Applications \\
\hline Qasem and Shamsuddin(2011) & \multirow{7}{*}{ Classification } \\
\hline Luukka and Lampinen(2011) & \\
\hline Triguero et al.(2011) & \\
\hline Neri and Tirronen(2010) & \\
\hline Garc1 et al.(2012) & \\
\hline Bencherif et al.(2014) & \\
\hline Luo et al.(2015) & \\
\hline Zhong et al.(2013) & \multirow{3}{*}{ Clustering } \\
\hline Lin et al.(2019) & \\
\hline Kuo et al.(2013) & \\
\hline Khushaba et al.(2011) & \multirow{3}{*}{ Feature Selection } \\
\hline Al-Ani et al.(2013) & \\
\hline Nayak et al.(2020) & \\
\hline
\end{tabular}


Table 7: Image Processing

\begin{tabular}{|c|c|}
\hline Authors & Applications \\
\hline Das et al. (2009) & clusters in the image \\
\hline Ghosh et al.(2014) & Moving Object Detection \\
\hline Cruz-Aceves et al.(2013) & \multirow{2}{*}{ Image Segmentation } \\
\hline Ramadas et al.(2019) & \\
\hline Ali et al.(2014) & \multirow{2}{*}{ Multi-level Image Thresholding } \\
\hline Sarkar et al.(2015) & \\
\hline Al-Ani et al.(2013) & Feature Selection in Image Data \\
\hline Casella et al.(2019) & Range Image Registration \\
\hline Xu et al.(2014) & Sub-pixel Mapping \\
\hline Zamuda et al.(2011) & \multirow{2}{*}{ Animated Tree Reconstruction } \\
\hline Zamuda and Brest(2014) & \\
\hline Kang et al.(2013) & 3D Reconstruction from Uncalibrated Images \\
\hline Dhabal et al.(2021) & \multirow{2}{*}{ Image clarification } \\
\hline Guraksin et al.(2019) & \\
\hline
\end{tabular}

Table 8: Bioinformatics and Bio-medical Engineering

\begin{tabular}{|l|l|}
\hline \multicolumn{1}{|c|}{ Authors } & \multicolumn{1}{c|}{ Applications } \\
\hline Ali, Ahn, and Siarry(2014) & Hypoglycemia Detection \\
\hline De Falco(2013) & Rule Extraction from Medical Database \\
\hline Lei et al.(2014) & $\begin{array}{l}\text { Hippocampus localization in histological } \\
\text { images }\end{array}$ \\
\hline Mesejo et al.(2013) & Monitoring of obstructive sleep \\
\hline Sannino et al.(2014) & $\begin{array}{l}\text { Parameter Estimation of Biological } \\
\text { Systems }\end{array}$ \\
\hline Zhan et al.(2014)
\end{tabular}

Table 9: Electronics and Communication Engineering

\begin{tabular}{|l|l|}
\hline \multicolumn{1}{|c|}{ Authors } & \multicolumn{1}{c|}{ Applications } \\
\hline Almeida-Luz et al.(2011) & Mobile Location Management \\
\hline Chang(2012) & Non-linear System Modeling \\
\hline Kuila and Jana(2014) & Clustering of Wireless Sensory Network \\
\cline { 1 - 2 } Gundry et al.(2015) & Mobile Ad-hoc Networks \\
\cline { 1 - 2 } Li et al.(2013) & \multirow{2}{*}{ Optimal Fault Protection in Networks } \\
\hline Baraldi et al.(2016) & Placement of Wavelength Convertors. \\
\hline Lezama et al.(2012)
\end{tabular}




\begin{tabular}{|l|l|}
\hline \multicolumn{1}{|c|}{ Authors } & \multicolumn{1}{c|}{ Applications } \\
\hline Sengupta et al.(2012) & Sleep-scheduling in wireless sensor networks \\
\hline R. Li et al.(2011) & Electromagnetics including antenna design \\
\hline $\begin{array}{l}\text { Secmen and } \\
\text { Tasgetiren(2011) }\end{array}$ & \\
\hline
\end{tabular}

\section{The Analysis of The literature review}

This section presents an analysis of the review through analyzing the modifications done in the parameters of the algorithm, the applications that were solved using the algorithm, and the number of publications and their categories.

\subsection{The modifications of the parameters of DE}

The analysis begins by showing a list of modifications as seen inTable 10. The modificationscan be classified into five criteria, which are population, learning procedures, mutation functions, control parameters, and vector generation.Figure 2 shows a bar chart that visually shows the results of Table 10. The figure shows that Mallipeddi et al. (Mallipeddi et al., 2011), Wang et al. (Y. Wang et al., 2011), and Wu et al. (Wu et al., 2016) have presented the top number of modifications in the parameters of the algorithm. Figure 3 shows the percentage of modifications in the parameters of the algorithm. The figure shows that the lowest percentage of modificationsin parameters are in vector generation and population criteria. Figure 4 shows the percentage of publications of the modifications of the parameters of the algorithm.

Table 10: The list of modifications for each author

\begin{tabular}{|l|l|}
\hline \multicolumn{1}{|c|}{ Author } & \multicolumn{1}{c|}{ Modifications } \\
\hline \multirow{2}{*}{ Qin, Huang, and Suganthan(2008) } & Vector generation \\
\cline { 2 - 2 } & control parameters \\
\hline \multirow{2}{*}{ Das et al.(2009) } & Vector generation \\
\cline { 2 - 2 } & Mutation functions \\
\hline Gong et al.(Gong et al., 2010) & Learning procedures \\
\hline Brest and Maucec(Brest \& Maučec, 2011) & Learning procedures \\
\hline \multirow{3}{*}{ Mallipeddi et al.(2011) } & Mutation functions \\
\cline { 2 - 2 } & control parameters \\
\cline { 2 - 2 } & Vector generation \\
\hline \multirow{3}{*}{ Wang, Cai, and Zhang(2011) } & Learning procedures \\
\cline { 2 - 2 } & Vector generation \\
\cline { 2 - 2 } & control parameters \\
\hline L. Wang et al. (2012) & Learning procedures \\
\hline Caraffini et al.(2013) & Learning procedures \\
\hline Tanabe and Fukunaga(2013) & control parameters \\
\hline Tanabe and Fukunaga(Tanabe \& Fukunaga, 2014) & Population \\
\hline
\end{tabular}




\begin{tabular}{|l|l|}
\hline \multicolumn{1}{|c|}{ Author } & \multicolumn{1}{c|}{ Modifications } \\
\hline Cortés-Antonio et al.(2014) & Learning procedures \\
\hline $\begin{array}{l}\text { Ali Wagdy Mohamed(Ali Wagdy Mohamed, } \\
\text { 2015) }\end{array}$ & Mutation functions \\
\hline \multirow{2}{*}{ Wu et al. (Wu et al., 2016) } & Population \\
\cline { 2 - 2 } & Mutation functions \\
\cline { 2 - 2 } Ali W Mohamed et al.(2017) & Learning procedures \\
\cline { 2 - 2 } & coarning procedures \\
\cline { 2 - 2 } & Mutation functions \\
\hline Akararungruangkul \& Kaewman(2018) & Mutation functions \\
\hline Ali W. Mohamed et al. (Ali W. Mohamed et al., \\
2019) & Mutation functions \\
\hline \multirow{2}{*}{ Meng et al. (2019) } & Mutation functions \\
\cline { 2 - 2 } Stanovov et al. (2020) & control parameters \\
\cline { 2 - 2 } Centrol parameters \\
\hline \multirow{2}{*}{ Centeno-Telleria et al. (2021) } & Learning procedures \\
\hline
\end{tabular}

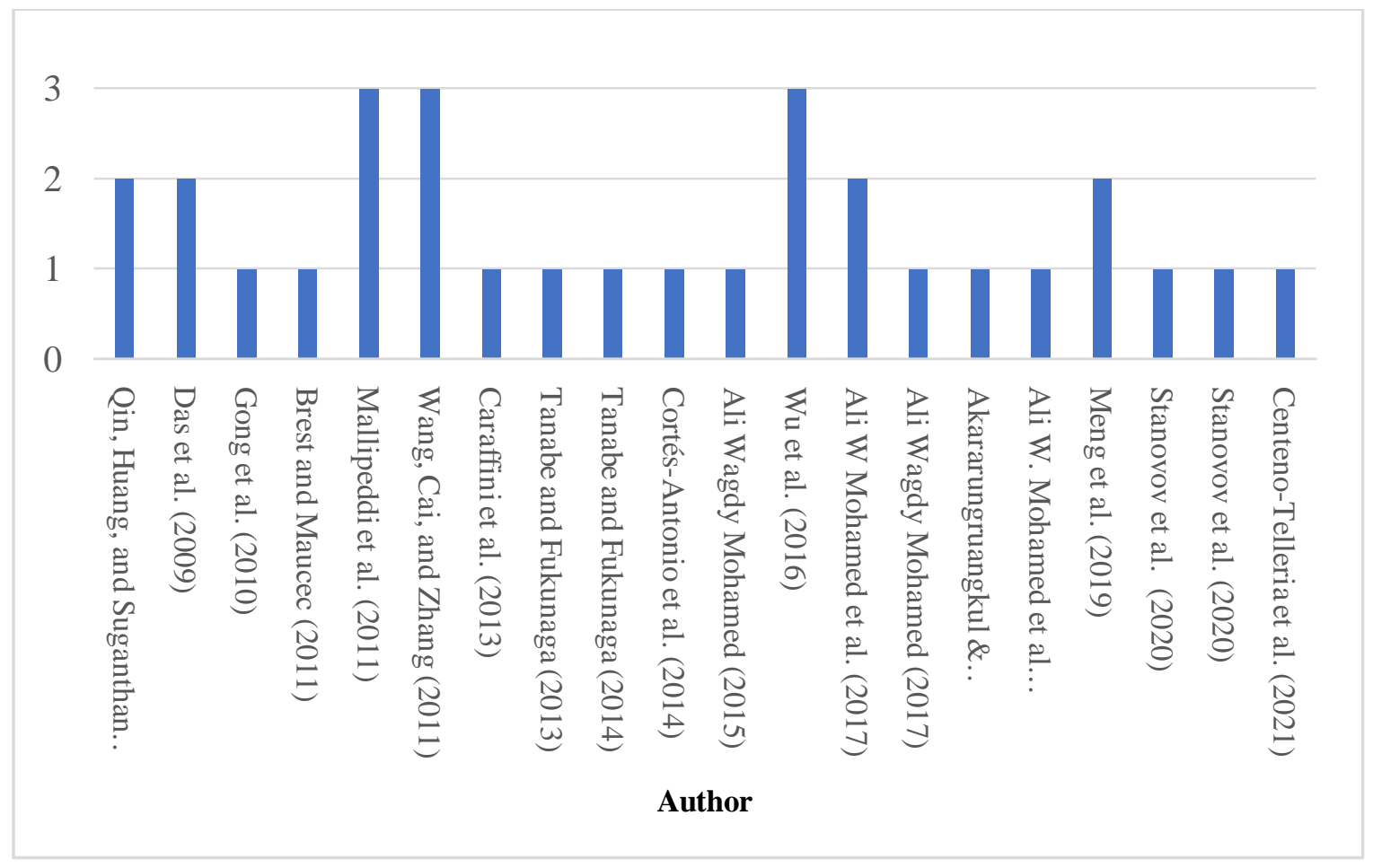

Figure 3: The relationship between authors and their modifications 


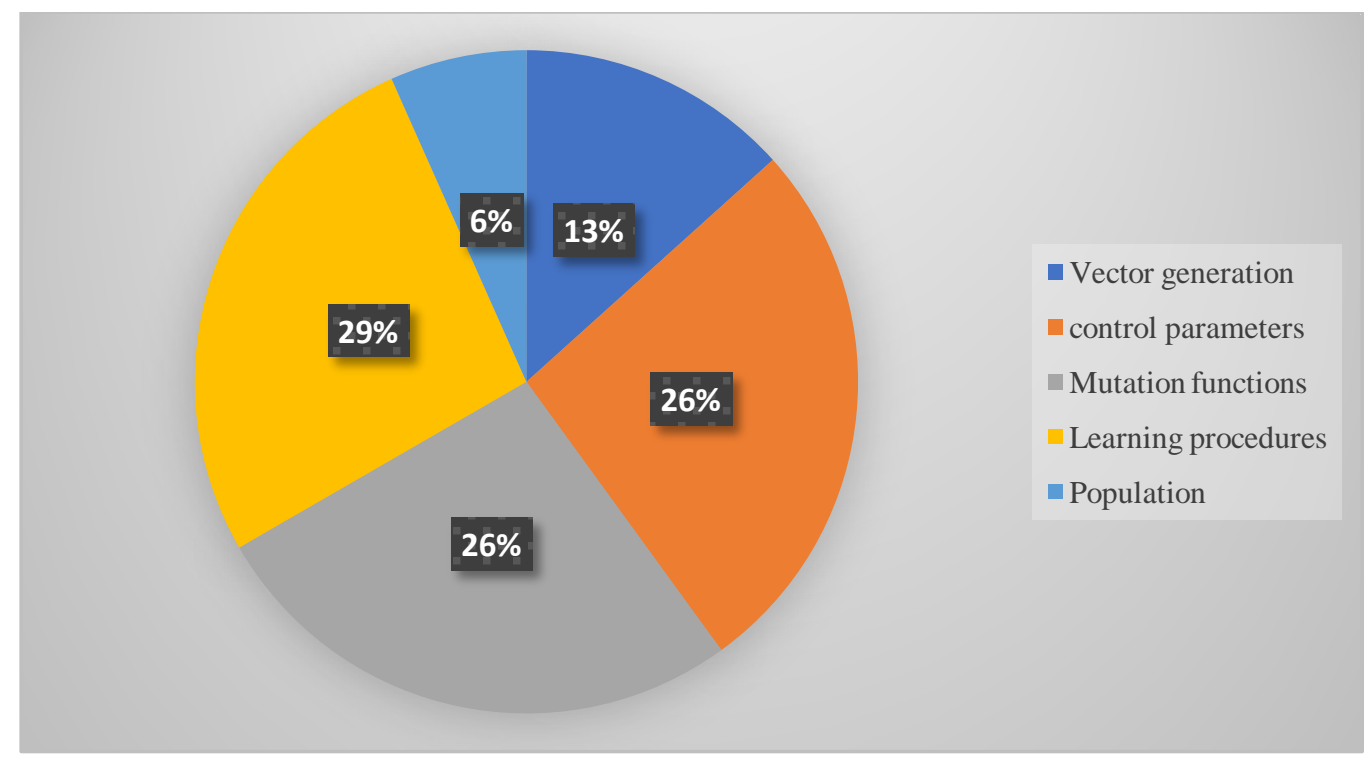

Figure 4: The percentage of modifications in parameters of DE

\subsection{The hybridization of DE with other algorithms}

This sub-section shows the algorithm that were hybridized with DE. Table 11 shows the hybridized approaches with DE in the previous work.

Table 11: The hybridized approaches with DE

\begin{tabular}{|l|c|}
\hline Hybridization & $\begin{array}{c}\text { The percentage } \\
\text { of researches }\end{array}$ \\
\hline Ant colony Optimization. & $9 \%$ \\
\hline The Ant Lion Optimizer. & $6 \%$ \\
\hline Artificial bee colony algorithm. & $6 \%$ \\
\hline Cuckoo search algorithm. & $12 \%$ \\
\hline Bat Algorithm. & $9 \%$ \\
\hline Firefly's Algorithm. & $6 \%$ \\
\hline Harmony search Algorithm. & $6 \%$ \\
\hline Simulated annealing Algorithm. & $6 \%$ \\
\hline Genetic Algorithm. & $12 \%$ \\
\hline Grey wolf optimizer. & $3 \%$ \\
\hline Whale optimization algorithm & $3 \%$ \\
\hline Particle swarm optimization algorithm & $9 \%$ \\
\hline BlackHole algorithms & $3 \%$ \\
\hline Biography-based optimization & $6 \%$ \\
\hline Hill climbing & $3 \%$ \\
\hline
\end{tabular}




\subsection{Applications Solved Using DE}

Figure 5 shows the percentage of the previous work of the applications that were solved using DE.

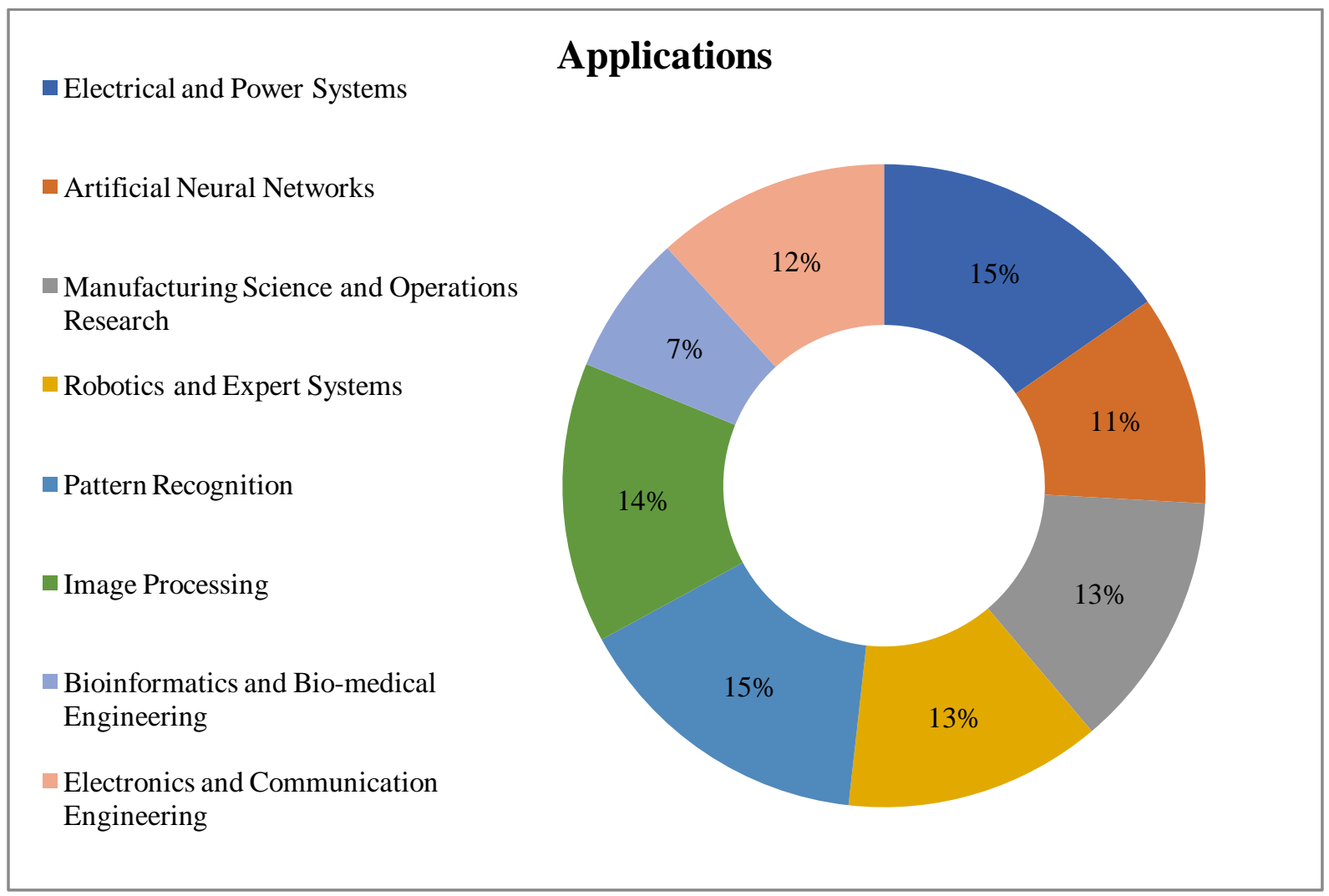

Figure 5:The percentage of publication according to applications of DE.

\subsection{Publication by Year}

Figure 6 shows the number of published papers per year in DE from 2008 to 2021.

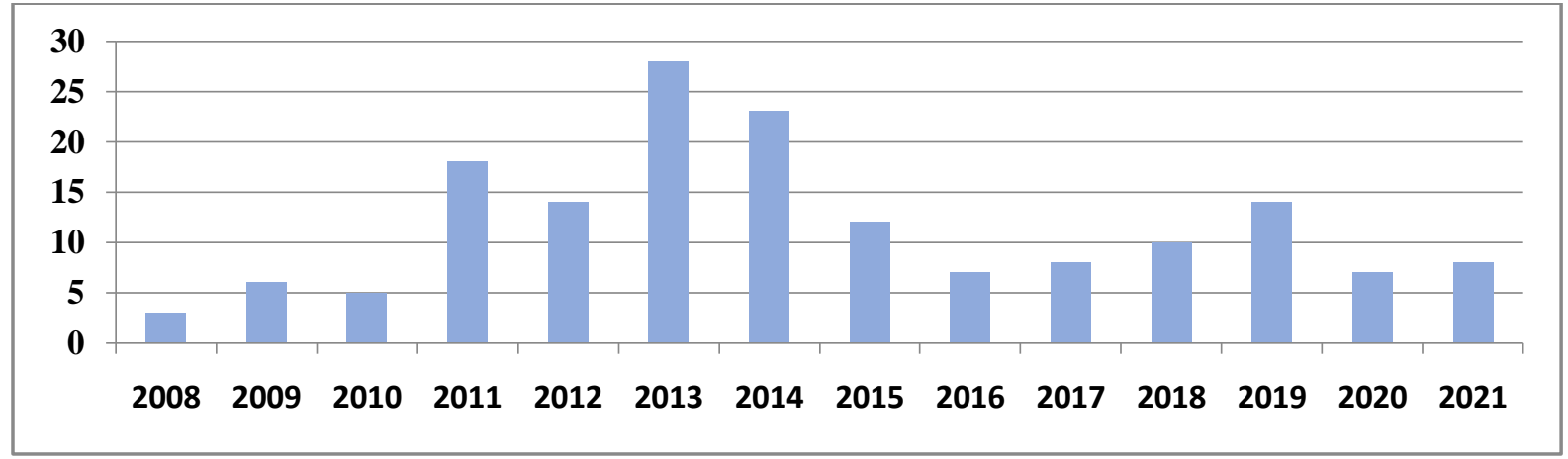

Figure 6:The number of Publications per year 


\section{Conclusion}

This study presents a review on differential evolution algorithm. The analysis of the review could help the researchers to have a clear view about the previous work through analyzing the modifications of the parameters or the algorithm, the hybridized approaches with DE, the applications that were solved using DE and the number of publications from 2008 to 2021. The analysis shows that Mallipeddi et al. (Mallipeddi et al., 2011), Wang et al. (Y. Wang et al., 2011), and Wu et al. (Wu et al., 2016) have presented the top number of modifications in the parameters of the algorithm. The analysis also shows that the lowest percentage of modifications in parameters are in vector generation and population parameters. Therefore, the recommendation in this point for future work is to have a highly focus on both of these parameters. Table 12 shows the hybridized approaches with DE. The researchers simply could hybridize some other algorithms that are not included in such table. The number published papers in DE until 2021 shows that such approach is still having special concentration from researchers as seen in figure 6.

\section{References}

Addawe, R., \& Magadia, J. (2014). Differential Evolution-Simulated Annealing (DESA) algorithm for fitting autoregressive models to data. OPT-i 2014 International Conference on Engineering and Applied Sciences Optimization. National Technical University, Kos Island, Greece.

Ahmadianfar, I., Kheyrandish, A., Jamei, M., \& Gharabaghi, B. (2021). Optimizing operating rules for multi-reservoir hydropower generation systems: An adaptive hybrid differential evolution algorithm. Renewable Energy, 167, 774-790.

Akararungruangkul, R., \& Kaewman, S. (2018). Modified Differential Evolution Algorithm Solving the Special Case of Location Routing Problem. Mathematical and Computational Applications, 23(3), 34. https://doi.org/10.3390/mca23030034

Aktulga, H. M., Fogarty, J. C., Pandit, S. A., \& Grama, A. Y. (2012). Parallel reactive molecular dynamics: Numerical methods and algorithmic techniques. Parallel Computing, 38(4-5), 245-259.

Al-Ani, A., Alsukker, A., \& Khushaba, R. N. (2013). Feature subset selection using differential evolution and a wheel based search strategy. Swarm and Evolutionary Computation, 9, 1526.

Ali, M., Ahn, C. W., \& Pant, M. (2014). Multi-level image thresholding by synergetic differential evolution. Applied Soft Computing, 17, 1-11.

Ali, M., Ahn, C. W., \& Siarry, P. (2014). Differential evolution algorithm for the selection of optimal scaling factors in image watermarking. Engineering Applications of Artificial Intelligence, 31, 15-26.

Ali, M., Pant, M., \& Abraham, A. (2009). A hybrid ant colony differential evolution and its application to water resources problems. 2009 World Congress on Nature \& Biologically 
Inspired Computing (NaBIC), 1133-1138.

Almeida-Luz, S. M., Vega-Rodríguez, M. A., Gómez-Púlido, J. A., \& Sánchez-Pérez, J. M. (2011). Differential evolution for solving the mobile location management. Applied Soft Computing, 11(1), 410-427.

Azad, M., Kalam, A., \& Fernandes, E. M. da G. P. (2012). A modified differential evolution based solution technique for economic dispatch problems.

Balamurugan, A., Priya, M. D., Janakiraman, S., \& Malar, A. C. J. (2021). Hybrid Stochastic Ranking and Opposite Differential Evolution-Based Enhanced Firefly Optimization Algorithm for Extending Network Lifetime Through Efficient Clustering in WSNs. Journal of Network and Systems Management, 29(3), 1-31.

Baraldi, P., Cannarile, F., Di Maio, F., \& Zio, E. (2016). Hierarchical k-nearest neighbours classification and binary differential evolution for fault diagnostics of automotive bearings operating under variable conditions. Engineering Applications of Artificial Intelligence, 56, $1-13$.

Basu, M. (2011). Bee colony optimization for combined heat and power economic dispatch. Expert Systems with Applications, 38(11), 13527-13531.

Bencherif, M. A., Bazi, Y., Guessoum, A., Alajlan, N., Melgani, F., \& AlHichri, H. (2014). Fusion of extreme learning machine and graph-based optimization methods for active classification of remote sensing images. IEEE Geoscience and Remote Sensing Letters, 12(3), 527-531.

Bhattacharya, A., \& Chattopadhyay, P. K. (2010). Hybrid differential evolution with biogeography-based optimization for solution of economic load dispatch. IEEE Transactions on Power Systems, 25(4), 1955-1964.

Birogul, S. (2019). Hybrid harris hawk optimization based on differential evolution (HHODE) algorithm for optimal power flow problem. IEEE Access, 7(January), 184468-184488. https://doi.org/10.1109/ACCESS.2019.2958279

Brest, J., \& Maučec, M. S. (2011). Self-adaptive differential evolution algorithm using population size reduction and three strategies. Soft Computing, 15(11), 2157-2174. https://doi.org/10.1007/s00500-010-0644-5

Cao, H., Zhou, K., \& Chen, X. (2015). Chatter identification in end milling process based on EEMD and nonlinear dimensionless indicators. International Journal of Machine Tools and Manufacture, 92, 52-59.

Caraffini, F., Neri, F., Cheng, J., Zhang, G., Picinali, L., Iacca, G., \& Mininno, E. (2013). Superfit multicriteria adaptive differential evolution. 2013 IEEE Congress on Evolutionary Computation, 1678-1685.

Casella, A., De Falco, I., Della Cioppa, A., Scafuri, U., \& Tarantino, E. (2019). Exploiting multicore and GPU hardware to speed up the registration of range images by means of differential evolution. Journal of Parallel and Distributed Computing, 133, 307-318.

Centeno-Telleria, M., Zulueta, E., Fernandez-Gamiz, U., Teso-Fz-betoño, D., \& Teso-Fz-betoño, 
A. (2021). Differential evolution optimal parameters tuning with artificial neural network. Mathematics, 9(4), 1-21. https://doi.org/10.3390/math9040427

Chang, W.-D. (2012). Differential evolution-based nonlinear system modeling using a bilinear series model. Applied Soft Computing, 12(11), 3401-3407.

Chen, C.-H., \& Yang, S.-Y. (2014). Neural fuzzy inference systems with knowledge-based cultural differential evolution for nonlinear system control. Information Sciences, 270, 154171.

Chen, C., Ugon, A., Sun, C., Chen, W., Philippe, C., \& Pinna, A. (2018). Towards a hybrid expert system based on sleep event's threshold dependencies for automated personalized sleep staging by combining symbolic fusion and differential evolution algorithm. IEEE Access, 7, 1775-1792.

Chen, Y., Mahalec, V., Chen, Y., Liu, X., He, R., \& Sun, K. (2015). Reconfiguration of satellite orbit for cooperative observation using variable-size multi-objective differential evolution. European Journal of Operational Research, 242(1), 10-20.

Chi, R., Su, Y., Qu, Z., \& Chi, X. (2019). A hybridization of cuckoo search and differential evolution for the logistics distribution center location problem. Mathematical Problems in Engineering, 2019.

Cortés-Antonio, P., Rangel-González, J., Villa-Vargas, L. A., Ramírez-Salinas, M. A., MolinaLozano, H., \& Batyrshin, I. (2014). Design and implementation of differential evolution algorithm on FPGA for double-precision floating-point representation. Acta Polytechnica Hungarica, 11(4), 139-153. https://doi.org/10.12700/aph.25.04.2014.04.9

Cruz-Aceves, I., Avina-Cervantes, J. G., Lopez-Hernandez, J. M., Rostro-Gonzalez, H., GarciaCapulin, C. H., Torres-Cisneros, M., \& Guzman-Cabrera, R. (2013). Multiple active contours guided by differential evolution for medical image segmentation. Computational and Mathematical Methods in Medicine, 2013.

Cui, Z., Gao, L., Ouyang, H., \& Li, H. (2013). Hybrid differential evolution harmony search algorithm for numerical optimization problems. 2013 25th Chinese Control and Decision Conference (CCDC), 2930-2933.

Das, S., Abraham, A., Chakraborty, U. K., \& Konar, A. (2009). Differential evolution using a neighborhood-based mutation operator. IEEE Transactions on Evolutionary Computation, 13(3), 526-553.

Das, S., Mullick, S. S., \& Suganthan, P. N. (2016). Recent advances in differential evolution-an updated survey. Swarm and Evolutionary Computation, 27, 1-30.

De Falco, I. (2013). Differential evolution for automatic rule extraction from medical databases. Applied Soft Computing, 13(2), 1265-1283.

Dhabal, S., Chakrabarti, R., Mishra, N. S., \& Venkateswaran, P. (2021). An improved image denoising technique using differential evolution-based salp swarm algorithm. Soft Computing, 25(3), 1941-1961.

Dhahri, H., Alimi, A. M., \& Abraham, A. (2012). Hierarchical multi-dimensional differential 
evolution for the design of beta basis function neural network. Neurocomputing, 97, 131140.

Ding, J., Zhou, J., Cai, W., \& Zheng, D. (2021). A modified hybrid algorithm based on black hole and differential evolution algorithms to search for the critical probabilistic slip surface of slopes. Computers and Geotechnics, 129, 103902.

Dragoi, E.-N., Curteanu, S., Galaction, A.-I., \& Cascaval, D. (2013). Optimization methodology based on neural networks and self-adaptive differential evolution algorithm applied to an aerobic fermentation process. Applied Soft Computing, 13(1), 222-238.

El Dor, A., Clerc, M., \& Siarry, P. (2012). A multi-swarm PSO using charged particles in a partitioned search space for continuous optimization. Computational Optimization and Applications, 53(1), 271-295.

Fister Jr, I., Fister, D., \& Yang, X.-S. (2013). A hybrid bat algorithm. ArXiv Preprint ArXiv:1303.6310.

Fouad, A. (2014). A novel hybrid genetic differential evolution algorithm for constrained optimization problems. International Journal of Advanced Research in Artificial Intelligence, 3(6), 6-12. https://doi.org/10.14569/ijarai.2014.030602

Gao, W., \& Liu, S. (2011). Improved artificial bee colony algorithm for global optimization. Information Processing Letters, 111(17), 871-882.

Garc1, S., Triguero, I., Carmona, C. J., \& Herrera, F. (2012). Evolutionary-based selection of generalized instances for imbalanced classification. Knowledge-Based Systems, 25(1), 3-12.

Ghasemi, M., Aghaei, J., Akbari, E., Ghavidel, S., \& Li, L. (2016). A differential evolution particle swarm optimizer for various types of multi-area economic dispatch problems. Energy, 107, 182-195.

Ghosh, A., Mondal, A., \& Ghosh, S. (2014). Moving object detection using Markov random field and distributed differential evolution. Applied Soft Computing, 15, 121-136.

Glotić, A., Glotić, A., Kitak, P., Pihler, J., \& Tičar, I. (2014). Parallel self-adaptive differential evolution algorithm for solving short-term hydro scheduling problem. IEEE Transactions on Power Systems, 29(5), 2347-2358.

Glotić, A., \& Zamuda, A. (2015). Short-term combined economic and emission hydrothermal optimization by surrogate differential evolution. Applied Energy, 141, 42-56.

Gong, W., Cai, Z., Ling, C. X., \& Li, H. (2010). Enhanced differential evolution with adaptive strategies for numerical optimization. IEEE Transactions on Systems, Man, and Cybernetics, Part B (Cybernetics), 41(2), 397-413.

Gundry, S., Zou, J., Uyar, M. U., Sahin, C. S., \& Kusyk, J. (2015). Differential evolution-based autonomous and disruption tolerant vehicular self-organization in MANETs. Ad Hoc Networks, 25, 454-471.

Guraksin, G. E., Deperlioglu, O., \& Kose, U. (2019). A novel underwater image enhancement approach with wavelet transform supported by differential evolution algorithm. In Nature 
Inspired Optimization Techniques for Image Processing Applications (pp. 255-278). Springer.

Hachicha, N., Jarboui, B., \& Siarry, P. (2011). A fuzzy logic control using a differential evolution algorithm aimed at modelling the financial market dynamics. Information Sciences, 181(1), 79-91.

Jadon, S. S., Tiwari, R., Sharma, H., \& Bansal, J. C. (2017). Hybrid artificial bee colony algorithm with differential evolution. Applied Soft Computing, 58, 11-24.

Jigang, H., Hui, F., \& Jie, W. (2019). A PI controller optimized with modified differential evolution algorithm for speed control of BLDC motor. Automatika: Časopis Za Automatiku, Mjerenje, Elektroniku, Računarstvo i Komunikacije, 60(2), 135-148.

Kang, L., Wu, L., Chen, X., \& Yang, Y.-H. (2013). Practical structure and motion recovery from two uncalibrated images using $\varepsilon$ Constrained Adaptive Differential Evolution. Pattern Recognition, 46(5), 1466-1484.

Khushaba, R. N., Al-Ani, A., \& Al-Jumaily, A. (2011). Feature subset selection using differential evolution and a statistical repair mechanism. Expert Systems with Applications, 38(9), 11515-11526.

Kuila, P., \& Jana, P. K. (2014). A novel differential evolution based clustering algorithm for wireless sensor networks. Applied Soft Computing, 25, 414-425.

Kuo, R. J., Suryani, E., \& Yasid, A. (2013). Automatic clustering combining differential evolution algorithm and k-means algorithm. Proceedings of the Institute of Industrial Engineers Asian Conference 2013, 1207-1215.

Lei, B., Tan, E.-L., Chen, S., Ni, D., Wang, T., \& Lei, H. (2014). Reversible watermarking scheme for medical image based on differential evolution. Expert Systems with Applications, 41(7), 3178-3188.

Lezama, F., Castañón, G., \& Sarmiento, A. M. (2012). Differential evolution optimization applied to the wavelength converters placement problem in all optical networks. Computer Networks, 56(9), 2262-2275.

Li, R., Xu, L., Shi, X.-W., Zhang, N., \& Lv, Z.-Q. (2011). Improved differential evolution strategy for antenna array pattern synthesis problems. Progress In Electromagnetics Research, 113, 429-441.

Li, Y.-F., Sansavini, G., \& Zio, E. (2013). Non-dominated sorting binary differential evolution for the multi-objective optimization of cascading failures protection in complex networks. Reliability Engineering \& System Safety, 111, 195-205.

Liao, T. W., Egbelu, P. J., \& Chang, P. (2012). Two hybrid differential evolution algorithms for optimal inbound and outbound truck sequencing in cross docking operations. Applied Soft Computing, 12(11), 3683-3697.

Lin, Y., Dong, X., Zheng, L., Yan, Y., \& Yang, Y. (2019). A bottom-up clustering approach to unsupervised person re-identification. Proceedings of the AAAI Conference on Artificial Intelligence, 33(01), 8738-8745. 
Liu, M., Yao, X., \& Li, Y. (2020). Hybrid whale optimization algorithm enhanced with Lévy flight and differential evolution for job shop scheduling problems. Applied Soft Computing, 87, 105954.

Liu, Y., Wang, Z., Xu, Z., Yang, Y., \& Gao, S. (2019). Ant Lion-based random walk differential evolution algorithm for optimization and clustering. 2019 11th International Conference on Intelligent Human-Machine Systems and Cybernetics (IHMSC), 2, 62-66.

Lu, H.-C., Chang, M.-H., \& Tsai, C.-H. (2012). Parameter estimation of fuzzy neural network controller based on a modified differential evolution. Neurocomputing, 89, 178-192.

Luo, A.-L., Zhao, Y.-H., Zhao, G., Deng, L.-C., Liu, X.-W., Jing, Y.-P., Wang, G., Zhang, H.-T., Shi, J.-R., \& Cui, X.-Q. (2015). The first data release (DR1) of the LAMOST regular survey. Research in Astronomy and Astrophysics, 15(8), 1095.

Luukka, P., \& Lampinen, J. (2011). Differential evolution classifier in noisy settings and with interacting variables. Applied Soft Computing, 11(1), 891-899.

Mallipeddi, R., Suganthan, P. N., Pan, Q.-K., \& Tasgetiren, M. F. (2011). Differential evolution algorithm with ensemble of parameters and mutation strategies. Applied Soft Computing, 11(2), 1679-1696.

Meng, X., Gao, X., \& Liu, Y. (2015). A novel hybrid bat algorithm with differential evolution strategy for constrained optimization. International Journal of Hybrid Information Technology, 8(1), 383-396.

Meng, Z., Pan, J.-S., \& Tseng, K.-K. (2019). PaDE: An enhanced Differential Evolution algorithm with novel control parameter adaptation schemes for numerical optimization. Knowledge-Based Systems, 168, 80-99.

Mesejo, P., Ugolotti, R., Di Cunto, F., Giacobini, M., \& Cagnoni, S. (2013). Automatic hippocampus localization in histological images using differential evolution-based deformable models. Pattern Recognition Letters, 34(3), 299-307.

Mlakar, U., Potočnik, B., \& Brest, J. (2016). A hybrid differential evolution for optimal multilevel image thresholding. Expert Systems with Applications, 65, 221-232.

Mohamed, Ali W., Hadi, A. A., \& Jambi, K. M. (2019). Novel mutation strategy for enhancing SHADE and LSHADE algorithms for global numerical optimization. Swarm and Evolutionary Computation, 50, 100455. https://doi.org/10.1016/j.swevo.2018.10.006

Mohamed, Ali W, Hadi, A. A., Fattouh, A. M., \& Jambi, K. M. (2017). LSHADE with semiparameter adaptation hybrid with CMA-ES for solving CEC 2017 benchmark problems. 2017 IEEE Congress on Evolutionary Computation (CEC), 145-152.

Mohamed, Ali Wagdy. (2015). An improved differential evolution algorithm with triangular mutation for global numerical optimization. Computers \& Industrial Engineering, 85, 359375.

Mohamed, Ali Wagdy. (2017). Solving stochastic programming problems using new approach to Differential Evolution algorithm. Egyptian Informatics Journal, 18(2), 75-86. https://doi.org/10.1016/j.eij.2016.09.002 
MohammadZadeh, S., \& Sadjadi, S. (2017). A hybrid Fire Fly and differential evolution algorithm for optimization of a mixed repairable and non-repairable system reliability problem. Journal of Industrial and Systems Engineering, 10(special issue on Quality Control and Reliability), 59-77.

Mohsin, N. S., Abd, B. F., \& Alhamadani, R. S. (2021). A hybrid Grey Wolf optimizer with multi-population differential evolution for global optimization problems. Periodicals of Engineering and Natural Sciences (PEN), 9(2), 400-409.

Nama, S., \& Saha, A. K. (2018). A new hybrid differential evolution algorithm with selfadaptation for function optimization. Applied Intelligence, 48(7), 1657-1671.

Nayak, S. K., Rout, P. K., Jagadev, A. K., \& Swarnkar, T. (2020). Elitism based multi-objective differential evolution for feature selection: A filter approach with an efficient redundancy measure. Journal of King Saud University-Computer and Information Sciences, 32(2), 174187.

Naz, M., Iqbal, Z., Javaid, N., Khan, Z. A., Abdul, W., Almogren, A., \& Alamri, A. (2018). Efficient power scheduling in smart homes using hybrid grey wolf differential evolution optimization technique with real time and critical peak pricing schemes. Energies, 11(2), 384.

Neri, F., \& Tirronen, V. (2010). Recent advances in differential evolution: A survey and experimental analysis. In Artificial Intelligence Review (Vol. 33, Issues 1-2). https://doi.org/10.1007/s10462-009-9137-2

Niu, M., Wan, C., \& Xu, Z. (2014). A review on applications of heuristic optimization algorithms for optimal power flow in modern power systems. Journal of Modern Power Systems and Clean Energy, 2(4), 289-297.

Nyirarugira, C., \& Kim, T. (2013). Adaptive differential evolution algorithm for real time object tracking. IEEE Transactions on Consumer Electronics, 59(4), 833-838.

Pan, J.-S., Liu, N., \& Chu, S.-C. (2020). A hybrid differential evolution algorithm and its application in unmanned combat aerial vehicle path planning. IEEE Access, 8, 1769117712.

Pan, Q.-K., Wang, L., Gao, L., \& Li, W. D. (2011). An effective hybrid discrete differential evolution algorithm for the flow shop scheduling with intermediate buffers. Information Sciences, 181(3), 668-685.

Pandit, M., Srivastava, L., \& Sharma, M. (2015). Environmental economic dispatch in multi-area power system employing improved differential evolution with fuzzy selection. Applied Soft Computing, 28, 498-510.

Pant, M., Thangaraj, R., Grosan, C., \& Abraham, A. (2008). Hybrid differential evolutionparticle swarm optimization algorithm for solving global optimization problems. 2008 Third International Conference on Digital Information Management, 18-24.

Piotrowski, A. P. (2014). Differential evolution algorithms applied to neural network training suffer from stagnation. Applied Soft Computing, 21, 382-406. 
Ponsich, A., \& Coello, C. A. C. (2013). A hybrid differential evolution-tabu search algorithm for the solution of job-shop scheduling problems. Applied Soft Computing, 13(1), 462-474.

Prado, R. S., Silva, R. C. P., Neto, O. M., Guimarães, F. G., Sanches, D. S., London Jr, J. B. A., \& Delbem, A. C. B. (2014). Differential evolution using ancestor tree for service restoration in power distribution systems. Applied Soft Computing, 23, 498-508.

Qasem, S. N., \& Shamsuddin, S. M. (2011). Memetic elitist pareto differential evolution algorithm based radial basis function networks for classification problems. Applied Soft Computing, 11(8), 5565-5581.

Qin, A. K., Huang, V. L., \& Suganthan, P. N. (2008). Differential evolution algorithm with strategy adaptation for global numerical optimization. IEEE Transactions on Evolutionary Computation, 13(2), 398-417.

Raghunathan, T., \& Ghose, D. (2014). Differential evolution based 3-D guidance law for a realistic interceptor model. Applied Soft Computing, 16, 20-33.

Rahmat, N. A., \& Musirin, I. (2013). Differential evolution immunized ant colony optimization technique in solving economic load dispatch problem. Engineering, 5(1), 157-162.

Ramadas, M., Abraham, A., \& Kumar, S. (2019). FSDE-Forced Strategy Differential Evolution used for data clustering. Journal of King Saud University-Computer and Information Sciences, 31(1), 52-61.

Reddy, S. S. (2019). Optimal power flow using hybrid differential evolution and harmony search algorithm. International Journal of Machine Learning and Cybernetics, 10(5), 1077-1091.

Sabar, N. R., Chong, S. Y., \& Kendall, G. (2015). A Hybrid Differential Evolution Algorithm Game Theory for the Berth Allocation Problem. 2, 77-87. https://doi.org/10.1007/978-3319-13356-0_7

Sannino, G., De Falco, I., \& De Pietro, G. (2014). Monitoring obstructive sleep apnea by means of a real-time mobile system based on the automatic extraction of sets of rules through differential evolution. Journal of Biomedical Informatics, 49, 84-100.

Sarbazfard, S., \& Jafarian, A. (2016). A hybrid algorithm based on firefly algorithm and differential evolution for global optimization. International Journal of Advanced Computer Science and Applications, 7(6), 95-106.

Sarkar, S., Das, S., \& Chaudhuri, S. S. (2015). A multilevel color image thresholding scheme based on minimum cross entropy and differential evolution. Pattern Recognition Letters, 54, 27-35.

Saruhan, H. (2014). Differential evolution and simulated annealing algorithms for mechanical systems design. Engineering Science and Technology, an International Journal, 17(3), 131136.

Sayah, S., \& Hamouda, A. (2011). Adaptive Differential Evolution Approach for Constrained Economic Power Dispatch with Prohibited Operating Zones. Leonardo Journal of Sciences, 19, 13-26. 
Secmen, M., \& Tasgetiren, M. F. (2011). A differential evolution algorithm for the extraction of complex natural resonance frequencies of electromagnetic targets. International Conference on Intelligent Computing, 131-138.

Sengupta, S., Das, S., Nasir, M., Vasilakos, A. V, \& Pedrycz, W. (2012). An evolutionary multiobjective sleep-scheduling scheme for differentiated coverage in wireless sensor networks. IEEE Transactions on Systems, Man, and Cybernetics, Part C (Applications and Reviews), 42(6), 1093-1102.

Sethanan, K., \& Jamrus, T. (2020). Hybrid differential evolution algorithm and genetic operator for multi-trip vehicle routing problem with backhauls and heterogeneous fleet in the beverage logistics industry. Computers \& Industrial Engineering, 146, 106571.

Shamekhi, A. (2013). An Improved Differential Evolution Optimization Algorithm. International Journal of Research and Review in Applied Science, 15(2), 132-145.

Singh, D., Kumar, V., \& Kaur, M. (2020). Classification of COVID-19 patients from chest CT images using multi-objective differential evolution-based convolutional neural networks. European Journal of Clinical Microbiology \& Infectious Diseases, 39(7), 1379-1389.

Singh, U. P., \& Jain, S. (2018). Optimization of neural network for nonlinear discrete time system using modified quaternion firefly algorithm: case study of Indian currency exchange rate prediction. Soft Computing, 22(8), 2667-2681.

Sivasubramani, S., \& Swarup, K. S. (2012). Multiagent based differential evolution approach to optimal power flow. Applied Soft Computing, 12(2), 735-740.

Sörensen, K., Sevaux, M., \& Glover, F. (2018). A history of metaheuristics. Handbook of Heuristics, 2-2, 791-808. https://doi.org/10.1007/978-3-319-07124-4_4

Stanovov, V., Akhmedova, S., \& Semenkin, E. (2020). Differential evolution with linear bias reduction in parameter adaptation. Algorithms, 13(11), 1-17. https://doi.org/10.3390/a13110283

Storn, R., \& Price, K. (1996). Minimizing the real functions of the ICEC'96 contest by differential evolution. Proceedings of IEEE International Conference on Evolutionary Computation, 842-844.

Subudhi, B., \& Jena, D. (2011). A differential evolution based neural network approach to nonlinear system identification. Applied Soft Computing, 11(1), 861-871.

Tanabe, R., \& Fukunaga, A. (2013). Success-history based parameter adaptation for differential evolution. 2013 IEEE Congress on Evolutionary Computation, 71-78.

Tanabe, R., \& Fukunaga, A. S. (2014). Improving the search performance of SHADE using linear population size reduction. 2014 IEEE Congress on Evolutionary Computation (CEC), 1658-1665.

Tang, L., Zhao, Y., \& Liu, J. (2013). An improved differential evolution algorithm for practical dynamic scheduling in steelmaking-continuous casting production. IEEE Transactions on Evolutionary Computation, 18(2), 209-225. 
Triguero, I., Derrac, J., Garcia, S., \& Herrera, F. (2011). A taxonomy and experimental study on prototype generation for nearest neighbor classification. IEEE Transactions on Systems, Man, and Cybernetics, Part C (Applications and Reviews), 42(1), 86-100.

Ugolotti, R., \& Cagnoni, S. (2013). Differential evolution based human body pose estimation from point clouds. Proceedings of the 15th Annual Conference on Genetic and Evolutionary Computation, 1389-1396.

Ugolotti, R., Nashed, Y. S. G., Mesejo, P., Ivekovič, Š., Mussi, L., \& Cagnoni, S. (2013). Particle swarm optimization and differential evolution for model-based object detection. Applied Soft Computing, 13(6), 3092-3105.

Vasile, M., Minisci, E., \& Locatelli, M. (2011). An inflationary differential evolution algorithm for space trajectory optimization. IEEE Transactions on Evolutionary Computation, 15(2), 267-281.

Vincent, L. W. H., \& Ponnambalam, S. G. (2012). A differential evolution-based algorithm to schedule flexible assembly lines. IEEE Transactions on Automation Science and Engineering, 10(4), 1161-1165.

Wang, B., Sun, Y., Xue, B., \& Zhang, M. (2018). A hybrid differential evolution approach to designing deep convolutional neural networks for image classification. Australasian Joint Conference on Artificial Intelligence, 237-250.

Wang, L., Fu, X., Mao, Y., Menhas, M. I., \& Fei, M. (2012). A novel modified binary differential evolution algorithm and its applications. Neurocomputing, 98, 55-75.

Wang, T., Zhang, G., Zhao, J., He, Z., Wang, J., \& Pérez-Jiménez, M. J. (2014). Fault diagnosis of electric power systems based on fuzzy reasoning spiking neural $\mathrm{P}$ systems. IEEE Transactions on Power Systems, 30(3), 1182-1194.

Wang, W.-L., Wang, H.-Y., Zhao, Y.-W., Zhang, L.-P., \& Xu, X.-L. (2013). Parallel machine scheduling with splitting jobs by a hybrid differential evolution algorithm. Computers \& Operations Research, 40(5), 1196-1206.

Wang, X., \& Xu, G. (2011). Hybrid differential evolution algorithm for traveling salesman problem. Procedia Engineering, 2716-2720. https://doi.org/10.1016/j.proeng.2011.08.511

Wang, Y., Cai, Z., \& Zhang, Q. (2011). Differential evolution with composite trial vector generation strategies and control parameters. IEEE Transactions on Evolutionary Computation, 15(1), 55-66.

Wu, G., Mallipeddi, R., Suganthan, P. N., Wang, R., \& Chen, H. (2016). Differential evolution with multi-population based ensemble of mutation strategies. Information Sciences, 329(December 2017), 329-345. https://doi.org/10.1016/j.ins.2015.09.009

Xu, X., Zhong, Y., \& Zhang, L. (2014). A sub-pixel mapping method based on an attraction model for multiple shifted remotely sensed images. Neurocomputing, 134, 79-91.

Yildiz, A. R. (2013a). Hybrid Taguchi-differential evolution algorithm for optimization of multipass turning operations. Applied Soft Computing, 13(3), 1433-1439. 
Yildiz, A. R. (2013b). Optimization of multi-pass turning operations using hybrid teaching learning-based approach. The International Journal of Advanced Manufacturing Technology, 66(9-12), 1319-1326.

Zamuda, A., \& Brest, J. (2014). Vectorized procedural models for animated trees reconstruction using differential evolution. Information Sciences, 278, 1-21.

Zamuda, A., Brest, J., Bošković, B., \& Žumer, V. (2011). Differential evolution for parameterized procedural woody plant models reconstruction. Applied Soft Computing, 11(8), 4904-4912.

Zamuda, A., \& Sosa, J. D. H. (2014). Differential evolution and underwater glider path planning applied to the short-term opportunistic sampling of dynamic mesoscale ocean structures. Applied Soft Computing, 24, 95-108.

Zamuda, A., \& Sosa, J. D. H. (2019). Success history applied to expert system for underwater glider path planning using differential evolution. Expert Systems with Applications, 119, 155-170.

Zhan, C., Situ, W., Yeung, L. F., Tsang, P. W.-M., \& Yang, G. (2014). A parameter estimation method for biological systems modelled by ODE/DDE models using spline approximation and differential evolution algorithm. IEEE/ACM Transactions on Computational Biology and Bioinformatics, 11(6), 1066-1076.

Zhang, G., Cheng, J., Gheorghe, M., \& Meng, Q. (2013). A hybrid approach based on differential evolution and tissue membrane systems for solving constrained manufacturing parameter optimization problems. Applied Soft Computing, 13(3), 1528-1542.

Zhang, X., Xue, Y., Lu, X., \& Jia, S. (2018). Differential-evolution-based coevolution ant colony optimization algorithm for bayesian network structure learning. Algorithms, 11(11), 188.

Zhang, Z., Ding, S., \& Jia, W. (2019). A hybrid optimization algorithm based on cuckoo search and differential evolution for solving constrained engineering problems. Engineering Applications of Artificial Intelligence, 85, 254-268.

Zhang, Z., Dong, Y., \& Gao, T. (2016). A hybrid method based on cuckoo search and krill herd optimization with differential evolution. 2016 13th Web Information Systems and Applications Conference (WISA), 138-143.

Zhao, Y., Li, W., Feng, S., Ochieng, W. Y., \& Schuster, W. (2014). An improved differential evolution algorithm for maritime collision avoidance route planning. Abstract and Applied Analysis, 2014.

Zhong, Y., Zhang, S., \& Zhang, L. (2013). Automatic fuzzy clustering based on adaptive multiobjective differential evolution for remote sensing imagery. IEEE Journal of Selected Topics in Applied Earth Observations and Remote Sensing, 6(5), 2290-2301. 